\title{
Erratum
}

\section{Erratum to "Torsion of Hydrosalpinx with Concurrent Acute Cholecystitis: Case Report and Review of Literature"}

\author{
Preeti R. John ${ }^{1,2}$ and Amelia M. Pasley ${ }^{3}$ \\ ${ }^{1}$ Baltimore VA Medical Center, 10 North Greene Street, 5C-119, Baltimore, MD 21201, USA \\ ${ }^{2}$ Department of Surgery, University of Maryland Medical Center, Baltimore, MD, USA \\ ${ }^{3}$ University of Maryland Medical Center, Baltimore, MD, USA \\ Correspondence should be addressed to Preeti R. John; preeti.john@va.gov \\ Received 17 August 2017; Accepted 28 September 2017; Published 28 December 2017 \\ Copyright ( $\odot 2017$ Preeti R. John and Amelia M. Pasley. This is an open access article distributed under the Creative Commons \\ Attribution License, which permits unrestricted use, distribution, and reproduction in any medium, provided the original \\ work is properly cited.
}

In the article titled "Torsion of Hydrosalpinx with Concurrent Acute Cholecystitis: Case Report and Review of
Literature" [1], the figures of the study were missing. The figures are as follows.

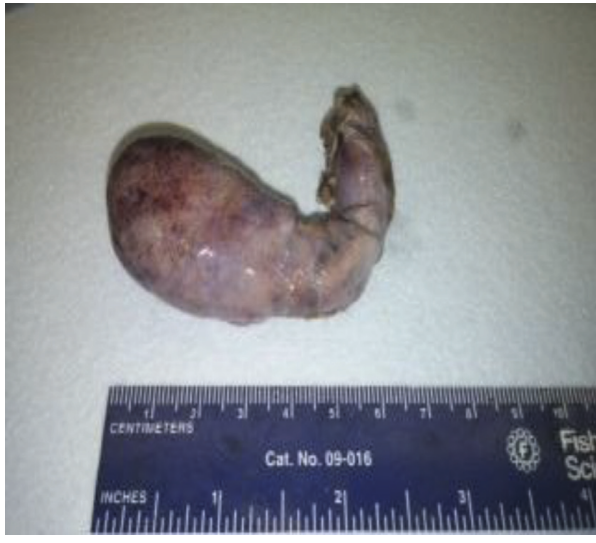

(a)

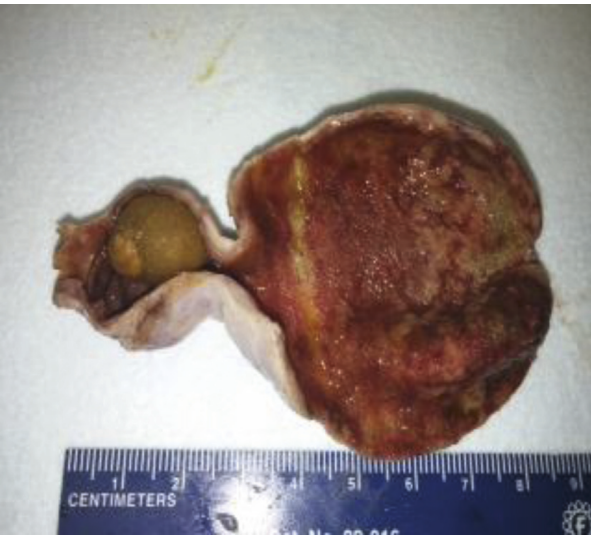

(b)

Figure 1: (a) Gall bladder. (b) Open gall bladder with stone impacted at infundibulum.

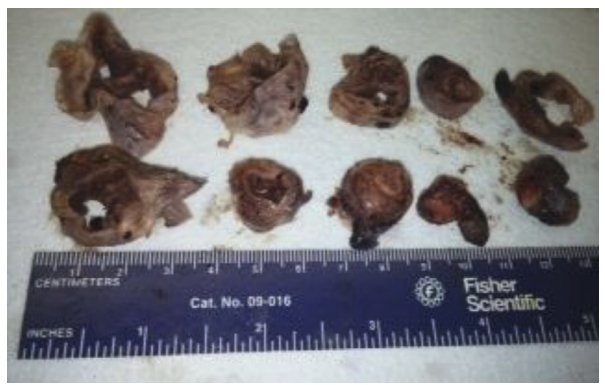

Figure 2: Fallopian tube with hydrosalpinx. 


\section{References}

[1] Preeti R. John and Amelia M. Pasley, "Torsion of Hydrosalpinx with Concurrent Acute Cholecystitis: Case Report and Review of Literature," Case Reports in Surgery, vol. 2016, Article ID 5424092, 4 pages, 2016. 


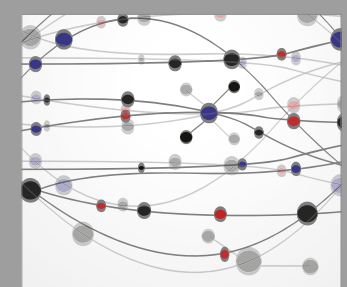

The Scientific World Journal
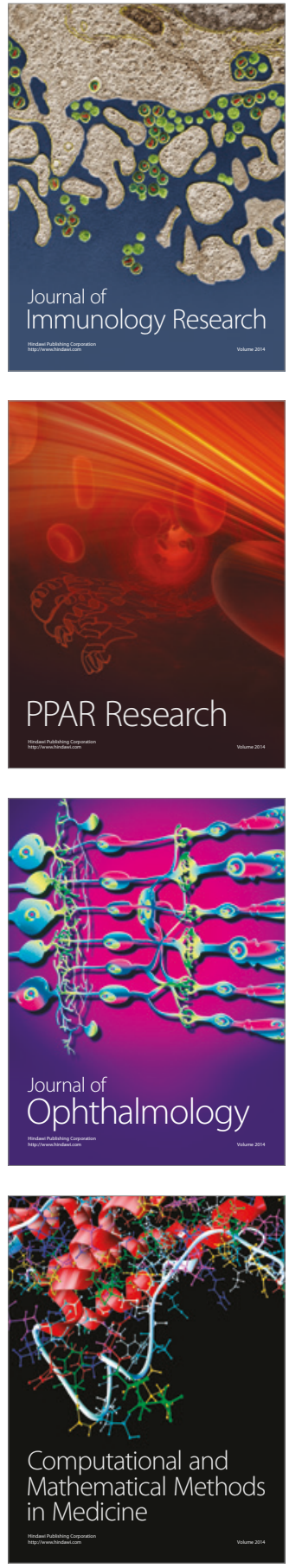

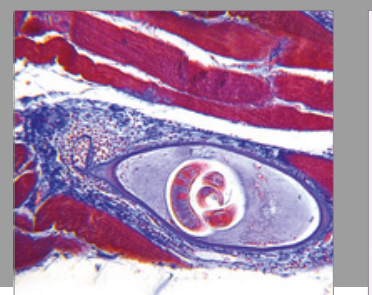

Gastroenterology Research and Practice
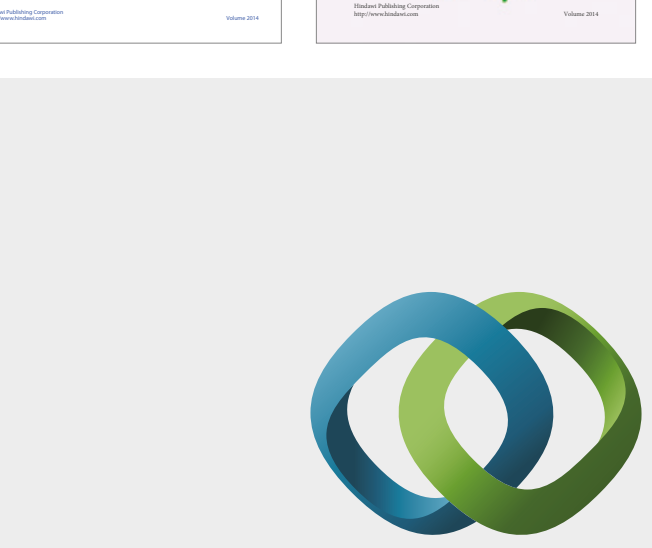

\section{Hindawi}

Submit your manuscripts at

https://www.hindawi.com
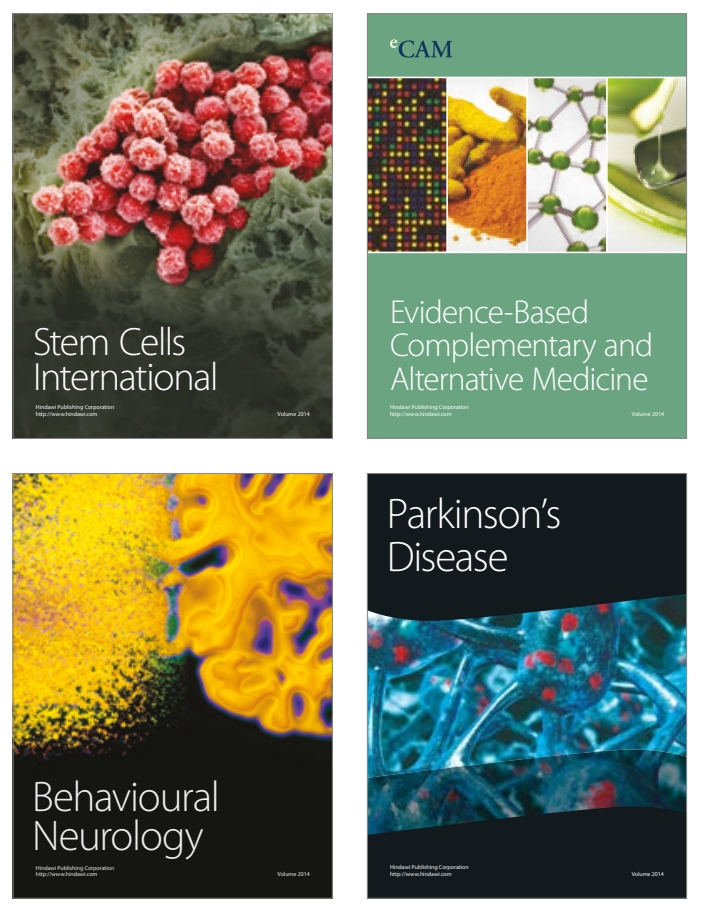
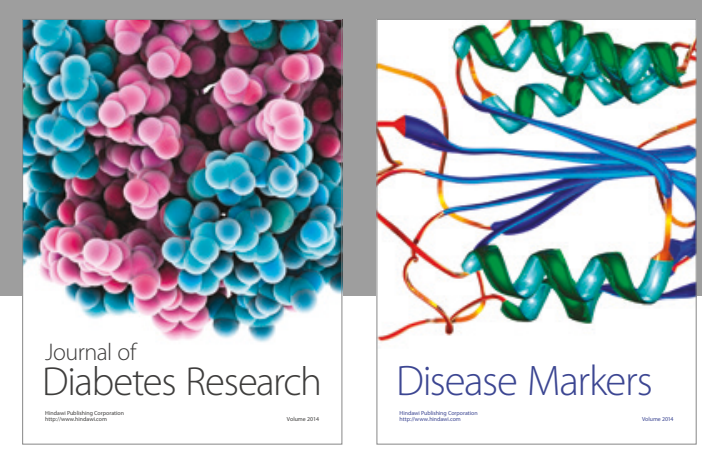

Disease Markers
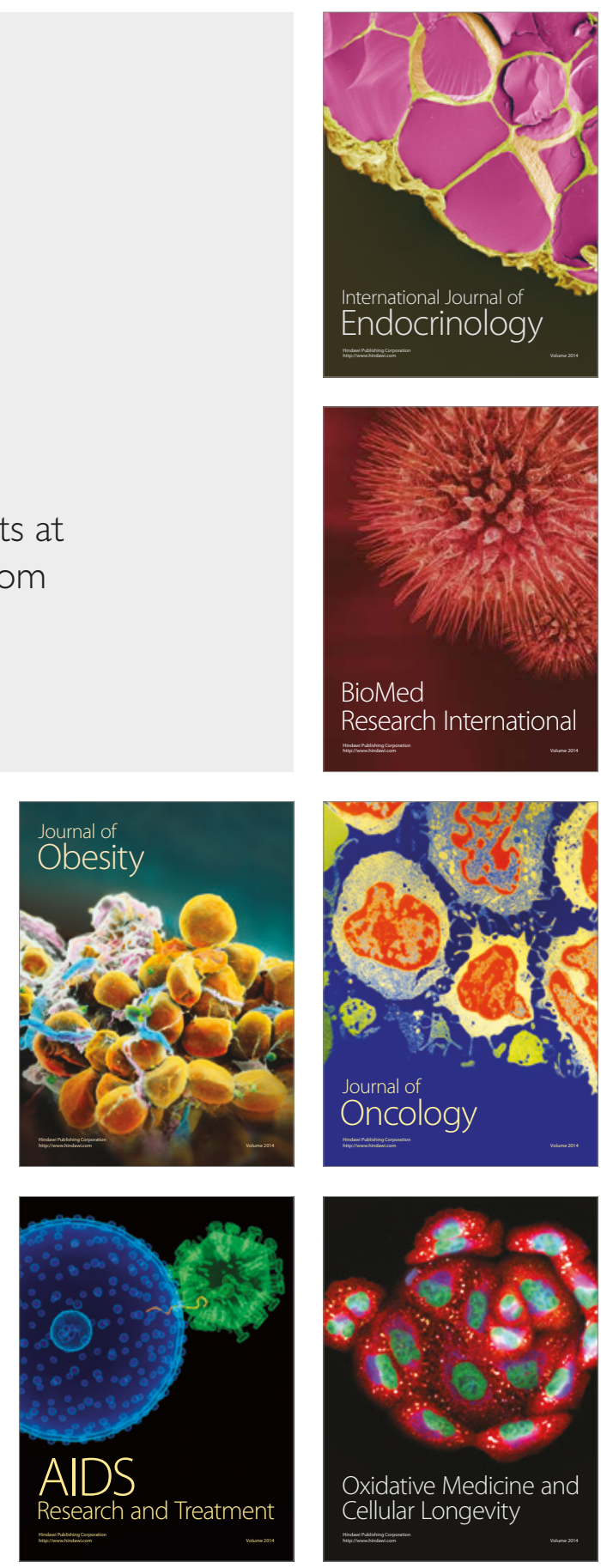